Ng, Ming Shan and Hall, Daniel M. (2019). "Toward Lean management for Digital Fabrication: a review of the shared practices of Lean, DfMA and DFAB." In: Proc. $27^{\text {th }}$ Annual Conference of the International. Group for Lean Construction (IGLC), Pasquire. C and Hamzeh FR. (ed.), Dublin, Ireland, pp. 725-736 DOI: https://doi.org/10.24928/2019/0204. Available at: <www.iglc.net>.

\title{
TOWARD LEAN MANAGEMENT FOR DIGITAL FABRICATION: A REVIEW OF THE SHARED PRACTICES OF LEAN, DFMA AND DFAB
}

\author{
Ming Shan $\mathrm{Ng}^{1}$ and Daniel Mark Hall ${ }^{2}$
}

\begin{abstract}
Digital Fabrication (dfab) is emerging as a new technical and computational approach for the architecture and construction industry. However, managing dfab requires processes to account for integrated design and construction processes. Lean construction management and design for manufacture and assembly (DfMA) offer two potential strategies for managing dfab. Although dfab, DfMA and lean have each been of wide interest among scholars, little research has examined their potential synergies. This paper conducts a literature review of all papers based on the authors' knowledge that discuss at least two of the three topics, and identifies common practices shared between the lean, DfMA and dfab. Two practices - design to target value and concurrent engineering - are found to be shared by all the three topics. Further, seven practices shared by two of the three topics: pullplanning, design-to-cost, standardisation, Jidoka, Just-in-Time, design-to-construct and knowledge sharing. This paper demonstrates the opportunities for synergies between lean, DfMA and dfab, and concludes with suggestions for future research to further investigate implementation of lean management for dfab in construction.
\end{abstract}

\section{KEYWORDS}

Lean Construction, Design Management, DfMA, Digital Fabrication, Literature Review

\section{INTRODUCTION}

There is slow technological development, productivity improvement and adoption of innovation in the construction industry (Hall et al. 2018; World Economic Forum 2016). Despite the great potential to boost productivity through advanced construction technologies such as digital fabrication (dfab), this requires a commitment of change in the industry. This includes technology, operations, and strategies to enhance integration and cooperation across the value chain. There is currently acceleration in digitalisation and computational development in research and in practice. Dfab, however, is still in an early

1 PhD student, Chair of Innovative and Industrial Construction, Dept. Civil, Env. and Geo. Eng., ETH Zurich, Stefano-Franscini-Platz 5, 8093 Zurich, Switzerland, +41 4463344 25, mng @ethz.ch.

2 Assistant Professor, Chair of Innovative and Industrial Construction, +41 44633 34 90, dhall@ethz.ch. 
stage of research. It lacks developed processes that can enable industry adoption at fullscale for projects.

Digital fabrication refers to data-driven production, which literally and technically turns data into things and things into data (Gershenfeld 2012). It includes the fields of robotics, drone-based technologies, rapid prototyping and additive manufacturing. Dfab is developed from Computer-Aided Design (CAD) and Computer-Aided Manufacturing (CAM) technologies, which started in the 1980s. Together with digital management system, dfab allows great freedom of design (Bock 2008). Dfab and construction automation in construction process enable digitalisation of design, delivery and project management onsite and off-site, and save time and effort by eliminating coordination steps of handing over shop drawings to the craftsmen (Fischer 2006; O'Connor et al. 2014; Bonwetsch 2012). Parametric modelling tools such as CATIA streamlines data exchange to manufacturing tools such as Computer Numerical Control (CNC), enabling the industry to accurately control production from digital models with digital-based interfaces between planning, engineering and production (Egan 1998; Buswell et al. 2007). There is a potential of dfab to improve productivity and return on investment by reducing wastes in time, materials and human resources in construction, in particular for bespoke or highly-customised building components (Bock 2004, 2008; de Soto et al. 2018a). Nevertheless, the industry is not yet familiar with full-scale implementation of dfab; dfab requires new approaches to project delivery and collaborative work systems to cope with the integrated design and construction processes (de Soto et al. 2018b).

Lean management has been introduced to the construction industry since 1990s to solve the problem of fragmentation and improve integration in design and construction processes. Adopted from the Toyota Production System, lean is a whole system approach which aims at value-adding, waste reduction, quality improvement, stakeholder's early involvement and supply-chain integration to optimise the entire process (Koskela et al. 2002; Womack \& Jones 1996; Ballard 2008). Studies show that poor control in early design stages reduce the overall performance and efficiencies (Hansen and Vanegas, 2003). This can be due to poor communication, missing information, scope changes, inadequate techincal knowledge of designers, or lack of early contractor's involvement (ECI) in the design development and procurement. Poor design management causes a snowball effect and incurs rework, delay, budget over-runs and reduced values in later stages of a project (Reifi and Emmitt 2013). In order to improve delivery of project values and performances, Ballard and Koskela (1998) proposed the agenda for lean design management research, of which approaches include Concurrent Engineering (CE), Set-based Design and Choosing by Advantage. These provide systematic requirements in early design stage to help stakeholders in communicaion and decision-making.

On the basis of lean, Macomber et al. (2012) and Ballard (2012) introduced the concept of Target Value Design (TVD). TVD is an integrative project management tool to keep the design and costs aligned with the client's target from early design phase (Kim and Lee 2010; Ballard 2011, Jung et al. 2012; Miron et al. 2015). Many research and case studies have demonstrated the benefits and effectiveness of lean implementation in conventional and integrated project delivery procurements, such as design-and-build and Integrated Project Delivery respectively. 
Design for manufacture and assembly (DfMA), which has also been introduced to the construction industry, helps to solve the problem of fragmentation in the industry and break the wall between design and construction from early design stage. The foundamental goal of DfMA is ease of manufacture and ease of assembly (Boothroyd et al. 2002). It is a design approach to boost productivity, quality assurance and cost/time/waste reduction at both management and operational levels (Laing O'Rourke 2013; Montali et al. 2018; Belay 2009; O'Brien et al. 2000; Fox et al. 2001; Bogue 2012). This requires communication, collaboration and concurrent knowledge transfer among different professions (Pasquire and Connolly 2003; Ulrich and Eppinger 2008; Bogus et al. 2006; Gerth et al. 2013). DfMA has also been proposed for automation, namely Design for Automation (DfA), to identify innovations in design with new technologies and digital system. DfA relies on not only accuracy and constrains of the machinery, but also coordination between design and production teams to assure design meets the needs and requirements of automation (Bridgewater 1993; Bogue 2012; Goulding et al. 2014).

\section{METHODOLOGY}

Although lean management, DfMA and dfab represent three different areas of research and implementation in construction, there is some evidence that they share similar principles and practices in their objectives to improve productivity and solve problems of fragmentation in the industry. The concept of practices refers to the "shared routines of behaviours" leading to the process of practical understanding and social structure development (Hall et al. 2018; Whittington 2006; Smets and Jarzabkowski 2013). However, the authors find little research that formally identifies and describes these shared principles and practices in specific detail.

This paper conducts a literature review to identify the common practices of lean, DfMA and dfab. To do so, the authors perform seach queries using Scopus and Google scholar databases. Search terms include the key words used in lean, DfMA and dfab scholarship (see Table 1). Additional selected papers are included based on the authors' knowledge. Journal articles and conference proceedings are included; books are excluded. It is because this paper focuses particularly on dfab technologies instead of the broader topics of digitalisation and computational design, papers about Building Information Modelling (BIM) and digital modelling are also excluded. In total, the authors identify ninteen papers that contain at least two of the keywords found in Table 1. These ninteen papers are categorised into two tiers; Tier 1 includes literatures with keywords of all three topics and tier 2 includes those of two of the three topics.

Table 1: Keywords used in the literature search

\begin{tabular}{ccc}
\hline LEAN CONSTRUCTION & DfMA & DIGITAL FABRICATION \\
Pull-Planning & Customisation & Automation \\
Just-in-Time & Modularisation & Robotics \\
Concurrent Engineering & Design for Automation & \\
\hline
\end{tabular}




\section{FINDINGS}

Given the principles of the three topics, the authors identify several practices that are used within each of the three approches (see Figure 2).

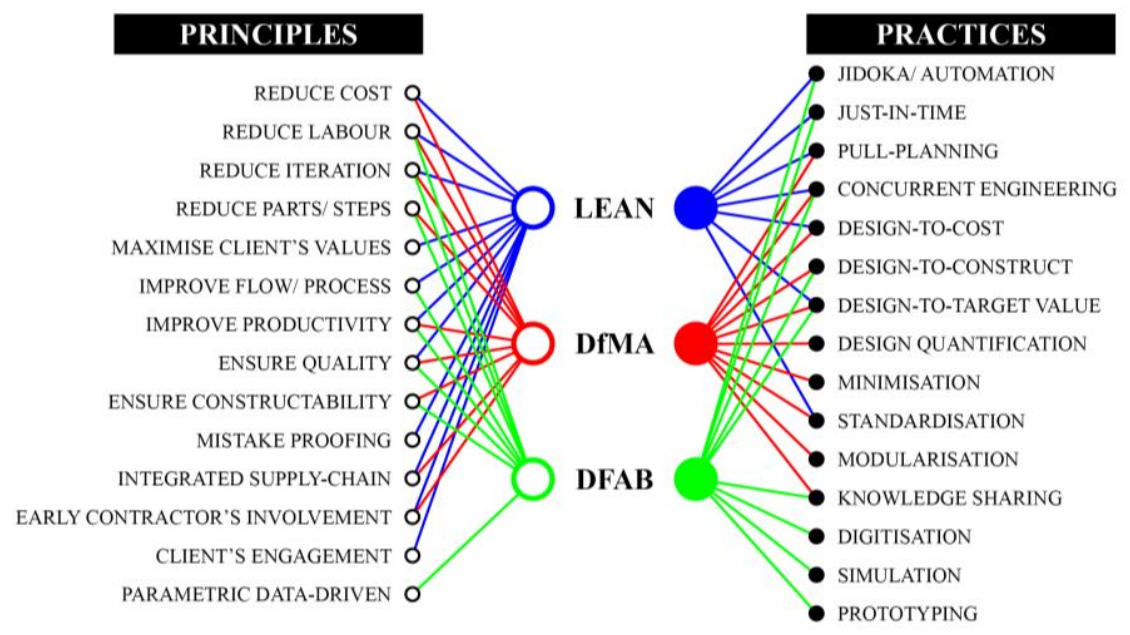

Figure 2: Principles and practices of lean, DfMA and dfab

\section{Practices of Lean Construction}

Based on literatures, lean practices include Just-in-Time (JIT), Jidoka, mistake proofing, standardisation and pull-planning to improve quality and productivity and reduce waste in cost, labour and iteration (Gerth et al. 2013; Fischer 2006); concurrent engineering (CE) (Koskela et al 2002; Koskela and Huovila 1997), client's engagement and early contractor's involvement (ECI) to manage design to meet cost and target values (Kim and Lee 2010; Miron et al. 2015). Integrated supply-chain also ensures stakeholder's collaboration to improve process from design to construction (Jung et al. 2012).

\section{Practices of Design for Manufacture And Assembly (DFMA)}

Through minimisation, standardisation and modularisation, DfMA quantifies design, reduces number of parts, steps of assembly and complexity, to reduce waste in materials, cost, time and labour, standardise components and reduce design variabilities (Boothroyd et al. 2002; O'Brien et al. 2000; Gerth et al. 2013; Bogue 2012; Fox et al. 2001; Gao et al. 2018). DfMA defines guidelines for constructability, knowledge sharing in manufacture (Ulrich and Eppinger 2008). Pull-planning can be applied for DfMA, upstream activities such as design decisions are made and pulled by downstream manufacturing process (Pasquire and Connolly 2003). CE helps to develop the product together for design-to-cost and design-to-target value in early design stage (Belay 2009; Bogus et al. 2006; O'Connor et al. 1987; Gerth et al. 2013; Goulding et al. 2014).

\section{Practices of Digital Fabrication (DFAB)}

Dfab allows automated progress and material tracking, JIT production and quality control during fabrication and on-site assembly (Nahangi and Haas 2016). Parametric design and manufacturing enables simultaneous design and fabrication data transfer, pre-construction 
simulation and prototyping, knowledge sharing and $\mathrm{CE}$ through object-oriented digital technologies to reduce production steps and ensure constructability and design to targetvalue (Martinez et al. 2008).

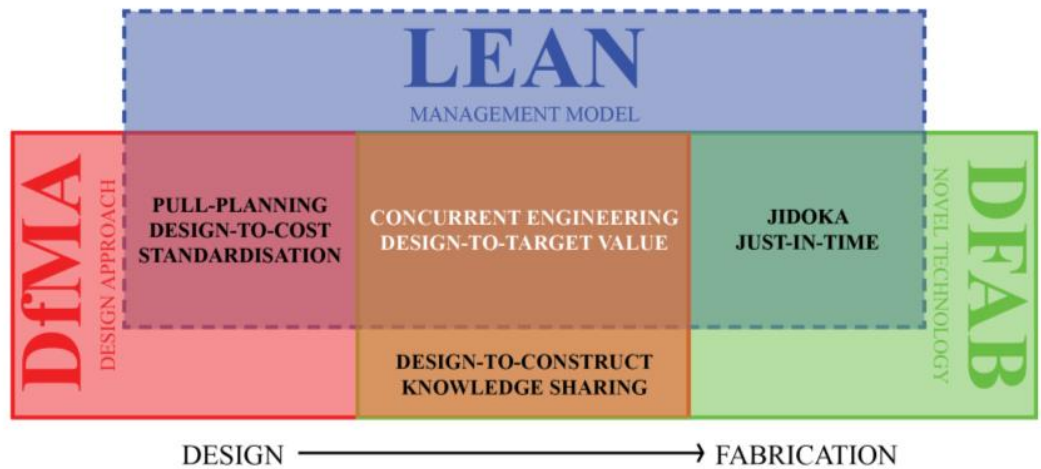

Figure 3: The shared practices of lean, DfMA and dfab.

\section{The Shared Practices of Lean, DFMA ANd DFaB}

Amongst all, the authors identify two shared practices of lean, DfMA and dfab. They are design-to-target value and concurrent engineering (see Figure 3). The shared practices of lean and DfMA are pull-planning, design-to-cost and standardisation; those of DfMA and dfab are knowledge sharing and design-to-construct; and those of lean and dfab are Jidoka and Just-in-Time.

\section{Tier 1 (Lean, DfMA and DFAB)}

Three literatures are categorised in Tier 1. Fischer (2006) discusses the integration of lean and 4D visualisation for self-aware automation for design for construction, i.e. DfMA. The lean concepts of concurrent and pull-driven planning lead to less rework and less waste of resources. Self-aware construction supports collaborative development of DfMA, construction automation and lean management; this forms the basis for digital fabrication and robotics. The knowledge formalised further helps to emerge computational construction activities.

Martinez et al. (2008) discuss the topics of lean, DfMA and robotic construction in the housing industry. They first analyse the factors and advantages of implementing automation in prefabrication with lean and DfMA principles. They propose a mobile factory using robots for on-site pre-fabrication, which enables lean concepts of JIT and flexible adaptation, and DfMA principles to integrate dwelling construction modules and the associated sub-structure requirements in early design stage.

O'Connor et al. (2014) discuss implementation of lean, DfMA and dfab in a relatively subtle way. They present the concept of PPMOF (prefabrication, preassembly, modularization and off-site fabrication) with key technologies of robotics, sensor-based control, schedule automation, Virtual Reality (VR) simulation and BIM. They list out 21 critical success factors (CSFs) for PPMOF, which include lean concepts, such as CE, ECI, supply chain integration and early cost-estimation for project's drivers alignment, and DfMA techniques, such as early constructability review, design for fabricator capability, manufacture process knowledge integration and reduction of modular interface. The CSFs 
listed provide a comprehensive reference for the shared practices of lean, DfMA and dfab discussed in this paper. The three selected Tier 1 literatures, however, hardly investigate in details the process and result of implementing lean, DfMA and dfab in construction.

\section{Tier 2 (Lean and DFAB)}

There are three literatures about lean and dfab in Tier 2. Nahangi and Haas (2016) present an algorithm to quantitatively track discrepancies between design and as-built assemblies. This automated detection system helps to reveal errors for corrective actions. This aligns with the lean concept of mistake proofing, pull-signalling, Genchi Genbutsu and Jidoka, although the term "lean" is not clearly mentioned in the context. Mocerino (2018) discusses how additive manufacturing, in line with lean construction and robotics, could improve productivity and efficiency, and reduce errors and costs through BIM and lean construction. Based on the case study of the DFAB HOUSE in Switzerland adopting the Last Planner System and lean principles, de Soto et al. (2018b) explore the collaborative work culture with dfab and the new roles created for dfab in construction.

\section{Tier 2 (Lean and DfMA)}

For Tier 2, seven articles discuss lean and DfMA. Gann (1996) investigates implementation of lean in industrialised housing from manufacturing to the final point of assembly in Japan. "Dimensional coordination" with DfMA principles, based on the size of factory-made components, defines grids and modular of the building design. Pasquire and Connolly (2003) propose three steps of DfMA with pull system from design to construction stage, and demonstrate that DfMA with a pull system help to address customer's values, solve buildability issues, reduce lead time and achieve a better integration of design and construction. Based on client's values and manufacturability, Bogus et al. (2006), propose "overlapping design strategy", which includes overdesign, no iteration, optimisation, setbased design and decomposition. This strategy requires overlapping of upstream and downstream activities and helps to reduce costs and risks. Gerth et al. (2013) state that lean and DfMA share the same key principles of reducing waste and cost and collaborative work during the development process. They propose Design for Construction (DfC) based on DfMA. DfC complements lean development concepts to transform individual knowledge into organisational knowledge and increases product and production performances. They also use "5-Why" and Ishikawa diagrams to identify the evaluation criteria for the design for constructability for the external wall.

Goulding et al. (2014) study a new approach and business model of off-site production in three major areas of off-site construction, namely process, technology and people, and their impacts on design, manufacturing and construction. They suggest a close collaboration in design and construction; all stakeholders should be involved in the early design phase. They highlight the requirement of integrating CE and DfMA in the overall design process by means of collaborative tools such as BIM. O'Connor et al. (2014) present seven concepts to improve constructability in design and procurement stages. These concepts include construction-driven JIT schedule, standardisation and modularisation, coreview of specification among stakeholders and downstream participation in upstream decision-making. Gao et al. (2018) explore the factors influencing adoption of DfMA in 
Singapore, and find that DfMA could be viewed as a process, an evaluation method and a technology. The lean concepts mentioned, such as JIT, reduction of speed and improvement of site management and concurrent engineering (CE), account for the three most influential factors of DfMA adoption.

\section{Tier 2 (DfMA and DFAB)}

There are six articles about DfMA and dfab in Tier 2. Based on DfMA, Bridgewater (1993) proposes Design for Automation (DfA) for factory-based production and on-site automation, to minimise the number of components for dfab such as robotics. In addition, he proposes guidelines for redesign of building systems for DfA and a new form of construction contracts and legal requirements for DfA. Bonwetsch (2012) states that CNC allows direct and automated transfer of design information to fabrication machines. Robotics emphasises the integration of design and construction, and helps to reduce cost and time of construction and add value in design quality. He highlights with examples the process of DfMA for robotics and integration of codes and design in early design phase. The parameters derived by dfab could influence the design outcomes and the design process; all physical constraints of fabrication had to be considered in the design process. Martinez et al. (2013) illustrate the design of the robotised Field Factory System based on DfMA principles, and its layout for production lines. For instance, the factory layout coped with the size of an $\mathrm{ABB}$ robot and its moving range, the Service Core has been analysed to improve the overall assembly time and quality.

Montali et al. (2018) explored the Knowledge-Based Engineering (KBE) approach using digital tools to support design through automation of reusable knowledge on façade design with DfMA principles. They found the currently available 2D and 3D digital tools are incapable to address the current design-manufacturability gap in the façade construction sector. The DfMA-based KBE for design automation is proposed to guide design from early design stage to increase quality, reduce delivery time and costs, reduce rework and support product development in construction. Arashpour et al. (2018) study the principles of DfMA using CNC milling and additive manufacturing, where parametric modelling supports collaborative works facilitated implementation of DfMA. De Soto et al. (2018a) investigate productivity of on-site robotic fabrication technology and quantitative analysis of cost and time during construction. They also find that dfab is able to produce complex ornament structures without additional cost, because dfab could build a component in a more integrated way with early input in the design phase, this aligns with DfMA principles.

\section{DISCUSSION}

The synergy of lean, DfMA and dfab practices is a starting point to begin to study how lean as a management model, DfMA as a design approach and dfab as a novel technology can be connected together in research to boost construction innovation. Foundational to the three topics of lean, DfMA and dfab to construction is the view that construction can be managed as a production system as opposed to past views of construction management as a form of craft administration (Stinchcombe 1959). The concept of prefabrication defines construction as a process of on-site or off-site manufacture and on-site assembly, and diffuses the distinction between construction and production (Gibb and Isack 2003). This 
requires $\mathrm{CE}$ and ECI for collective resources of manufacture and assembly knowledge during design stage to drive systemic innovation (Hall et al., 2018).

Furthermore, the practices identified reinforce the principle that ECI and client's engagement are the key enablers for implementing lean, DfMA and dfab. Contractors can provide commercially feasible design guidance since early stage to ease the following stages of manufacture and assembly (Vaz et al. 2008). The need of ECI in design is more significant for industrial construction, in particular with dfab. Pasquire and Connolly (2003) urge the need for client's engagement since design stage. During the design phase, clients need to express their concerns, make value assessments and decisions, freeze design early to provide reasonable lead time and take charge in supply-chain management for prefabrication (Gibb and Isack's 2003). Communication between clients and the supplychain helps to understand the design intents, constructability and project requirements to meet target values (Stump and Badurdeen 2012; Goulding et al. 2014). It is important for the clients to early select suitable contractors with certain skillsets such as dfab, not merely based on price but the ability to develop knowledge, experience for DfMA and innovations (Vaz et al. 2008). Adopting dfab in construction is usually a top-down decision, research on clients' engagement for dfab is however limited.

Design management and construction management are important as they incur waste and thus the overall project costs (Gerth et al. 2013). DfMA, CE and downstream's participation in upstream's decision-making help to optimise project and life-cycle costs (Omigbodun 2011). The on-going novel technology development in the construction industry such as dfab requires a re-consideration of the construction process, a new business thinking and an organisation reform of workforce to maximise project values and foster innovations (Bock 2008; Goulding et al. 2014; de Soto et al. 2018a; Mocerino 2018). While the industry is adopting integrated design process, such as IPD, and advanced technologies, such as robotic fabricators, existing management tools such as lean and DfMA, which have been introduced and implemented for decades, have to catch up and be tested in field. The authors believe lean principles and management model could work hand in hand with advanced design management strategies and business models such as DfMA, ECI and IPD, to foster advanced technologies such as ICT, robotics, additive manufacturing and Internet of Things in the industry.

\section{POTENTIAL FUTURE RESEARCH}

Dfab is still in its early stage of development, and research on design management tools to control design and production for dfab is limited. From the literature review, the authors note that research studies about lean for dfab and co-occurrence of lean, DfMA and dfab are limited, in comparison to emerging research about advancing digital technologies, such as BIM, cloud-based robotic fabrication and Industry 4.0. Based on the study here, the authors propose the following potential directions for future research:

- Lean design management for dfab. Work is needed to understand how implementation of lean facilitates dfab design development in terms of construction time, costs, quality and systemic innovation adoption. This research would utilise 
the shared practices of design-to-target value and CE, and also require those of DfMA such as design-to-construct and pull-planning in the design process for dfab.

- DfMA for bespoke building systems. This requires modularisation of non-standard components, which is the reverse concept of mass customisation. The uses of dfab and lean principles become more effective and significant. This research would utilise shared practices of design-to-target value, design-to-cost, design-toconstruct and CE.

- Reducing coordination costs of dfab. Scholars such as Bock (2004) suggests that construction robots could inherit high coordination costs, data processing requirements and energy consumption. Study on lean and DfMA to set up design guidelines to address the issues is needed. This would utilise shared practices of CE and knowledge sharing.

- Project organisation models for dfab. There is a need to understand how to adopt lean management, CE, client engagement and ECI for projects that use dfab. This could create new insights in business models and procurement methods. This would utilise shared practices of CE, pull-planning and knowledge sharing.

\section{CONCLUSION}

This paper reviews literatures which discuss lean, DfMA and dfab synchronously and identifies the common practices shared to demonstrate the potential synergies of them in the construction industry. Two shared practices are identified to be shared by lean, DfMA and dfab; they are: concurrent engineering and design-to-target value. Seven practices shared by two of the three topics are identified; they are: pull-planning, design-to-cost, standardisation, Jidoka, Just-in-Time, design-to-construct and knowledge sharing. Furthermore, this paper identifies lean design management for dfab, DfMA for bespoke building systems, coordination cost reduction for dfab, and project organisation models for dfab as future research areas.

\section{REFERENCES}

\section{TIER 1 LITERATURE}

Fischer, M. (2006). "Formalizing Construction Knowledge for Concurrent PerformanceBased Design." Intelligent Computing in Engineering and Architecture, EG-ICE 2006, Smith, I.F.C. (ed.), 186-205. Lecture Notes in Computer Science, vol 4200. Springer, Berlin.

Martinez, S., Jardon, A., Gimenez, A., Balaguer, C., Navarro, J.M. and Barcena, C. (2008). "Robotized lean assembly in the Building Industry.", In: Proc. of the 25th Int'l. Symposium on Automation and Robotics in Construction, Vilnius Lithuania, 195-201.

O'Connor, J.T., O'Brien, W.J., Choi, J.O. (2014). "Critical Success Factors and Enablers for Optimum and Maximum Industrial Modularization." Journal of Construction Engineering and Management, 140(6).

\section{TIER 2 LITERATURE}


Arashpour, M., Miletic, N., Williams, N. and Fang, Y. (2018). "Design for Manufacture and assembly in off-site construction: Advanced production of modular façade systems." In: Proc. 35 ${ }^{\text {th }}$ ISARC, Berlin, Germany, 224-229.

Bogus, S., Molenaar, K.R. and Diekmann, J.E. (2006). "Strategies for overlapping dependent design activities." Construction Management and Economics, 24(8), 829837.

Bonwetsch, T. (2012). "Robotic Assembly Processes as a Driver in Architectural Design." Nexus Network Journal, 14(3), 483-494.

Bridgewater, C. (1993). "Principles of design for automation applied to construction tasks." Automation in Construction, 2(1), 57-64.

O'Connor, J.T., Rusch, S.E. and Schulz, M.J. (1987). "Constructability concepts for engineering and procurement." Journal of Construction and Engineering Management, 113(2), 235-248.

Gann, D.M. (1996). "Construction as a manufacturing process? Similarities and Differences between industrialized housing and car production in Japan." Construction Management \& Economics, 14, 437-450.

Gao, S., Low, S.P. and Nair, K. (2018). "Design for Manufacturing and Assembly (DfMA): a preliminary study of factors influencing its adoption in Singapore." Architectural Engineering and Design Management, 14(6), 440-456.

Gerth, R., Boqvist, A., Bjelkemyr, M. and Lindberg, B. (2013). "Design for construction: utilizing production experiences in development." Construction Management and Economics, 31(2), 135-150.

Goulding, J.S., Rahimian, P., Arif, M. and Sharp, M. (2014). "New offsite production and business models in construction: priorities for the future research agenda." Architectural Engineering and Design Management, 11(3), 163-184.

Martinez, S., Jardon, A., Victores, J.G. and Balaguer, C. (2013). "Flexible Field Factory for Construction Industry." Assembly Automation, 33(2), 175-183.

Mocerino, C. (2018). " Digital revolution in efficient self-organization of buildings: towards intelligent robotics." In: Energy and Sustainability for Small Developing Economies, Funchal, Portugal.

Montali, J., Overend, M., Pelken, P.M. and Sauchelli, M. (2018). "Knowledge-Based Engineering in the design for manufacture of prefabricated facades: current gaps and future trends." Architectural Engineering and Design Management, 14(1-2), 78-94.

Nahangi, M. and Haas, C. (2016). "Skeleton-based discrepancy feedback for automated realignment of industrial assemblies." Automation in Construction, 61, 147-161.

Pasquire, C.L. and Connolly, G.E. (2003). "Design for manufacture and assembly." In: Proc. 11th Ann. Conf. of the Int'l. Group for Lean Construction, Blacksburg, U.S.A., 184194.

de Soto, B.G., Augstí-Juan, I., Hunhevicz, J., Joss, S., Graser, K., Habert, G. and Adey, B.T. (2018a). "Productivity of digital fabrication in construction: Cost and time analysis of a robotically built wall." Automation in Construction, 92, 297-311.

de Soto, B.G., Augstí-Juan, I., Hunhevicz, J., Habert, G. and Adey, B.T. (2018b). "Rethinking the roles in the AEC industry to accommodate digital fabrication." In: Proc. of the Creative Construction Conf. 2018, Ljubljana, Slovenia, 82-89. 


\section{AdDitional ReFerence}

Ballard, G. (2011). "Target Value Design: Current Benchmark." Lean Construction Journal, 79-84. < www.leanconstruction.org/media/docs/lcj/2011/LCJ_11_009.pdf>.

Ballard, G. (2012). "Target Value Design." In: Proc. Design 2012, the 12th Int'l Design Conf., Marjanovic, D., Storga, M. and Pavkovic, N. (ed.), Dubrovnik, Croatia, 11-20.

Ballard, G. and Koskela, L. (1998). "On the agenda of Design management research." In: Proc. 6th Ann. Conf. of the Int'l. Group for Lean Construction, Guaruja, Brazil, 1315.

Belay, A.M. (2009). "Design for Manufacturability and Concurrent Engineering for Product Development." World Academy of Science, Engineering and Technology, 49(1), 240-246.

Bock, T. (2004). "Construction robotics and automation: past-present-future." In: Proc. Automation Congress, World 15, 287-294.

Bock, T. (2008). "Construction automation and Robotics." Robotics and Automation in Construction, Balaguer, C. and Abderrahim, M. (ed.), InTech, 21-42.

Bogue, R. (2012). "Design for manufacture and assembly: background, capabilities and applications." Assembly Automation, 32(2), 112-118.

Boothroyd, G., Dewhurst, P. and Knight,W. (2002). Product Design for Manufacture and Assembly. 2nd ed. CRC Press Taylor \& Francis, Boca Raton, U.S.

O'Brien, M., Wakefield, R. and Beliveau, Y. (2000). "Industrializing the residential construction site." Center for Housing Research, Virginia Polytechnic Insititute and State University Blacksburg, Virginia.

Buswell, R.A., Soar, R.C., GIbb, A.G.F. and Thorpe, A. (2007). "Freeform Construction: Mega-scale Rapid Manufacturing for construction." Automation in Construction, 16, 224-231.

Egan, J. (1998). Rethinking Construction. The Report of the Construction Task Force, London, U.K.

Fox, S., Marsh, L. and Cockerham, G. (2001). " Design for manufacture: a strategy for successful application to buildings." Construction Management and Economics, 19(5), 493-502.

Gershenfeld, N. (2012). "How to make almost anything: the Digital Fabrication Revolution." Foreign A ffairs, 91(6), 43-57.

Gibb, A. and Isack, F. (2003). "Re-engineering through pre-assembly: client expectations and drivers." Building Research \& Information, 31(2), 146-160.

Hall, D.M., Algiers, A. and Levitt, R.E. (2018). "Identifying the Role of Supply Chain Integration Practices in the Adoption of Systemic Innovations." Journal of management in engineering, 34(6).

Hansen, K.L. and Vanegas, J. (2003). "Improving design quality through briefing automation." Building Research \& Information, 31(5), 379-386.

Jung, W., Ballard, G., Kim, Y.W., Han, S.H. (2012). "Understanding of Target Value Design for Integrated Project Delivery with the Context of Game Theory." Construction Research Congress 2012: Construction Challenges in a Flat World, 556563. 
Kim, Y. and Lee, H.W. (2010). "Analyzing User Costs in a Hospital: Methodological Implication of Space Syntax to Support Whole-Life Target Value Design.” In: Proc. 18th Ann. Conf. of the Int'l. Group for Lean Construction, Haifa, Israel, 93-102.

Koskela, L., Ballard, G., Howell, G.A. and Tommelein, I.D. (2002). "The foundations of lean construction." Design and Construction: Building in Value. Routledge, 211-226.

Koskela, L. and Howell, G.A. (2002). "The theory of project management: explanation to novel methods." In: Proc. 10th Ann. Conf. of the Int'l. Group for Lean Construction, Gramado, Brazil, 6-8.

Koskela, L. and Huovila, P. (1997). "Foundations of concurrent engineering." Concurrent Engineering in Construction CEC'97. 1st Int'1. Conf., Anumba, C. and Evbuomwan, N. (ed.), London, U.K., 22-32.

Liang O'Rourke (2013). "The future of DfMA is the future of construction." Engineering Excellent Journal, 77,76.

Macomber, H., Howell, G. and Barberio, J. (2012). "Target Value Design: Nine Foundational Practices for Delivering Surprising Client Value". [White paper]. <www.leanproject.com/access-whitepapers>.

Miron, L.I.G., Kaushik, A. and Koskela, L. (2015). "Target Value Design: The Challenge of Value Generation." In: Proc. 23rd Ann. Conf. of the Int'l. Group for Lean Construction, Perth, Australia, 815-825.

Omigbodun, A. (2001). "Value Engineering and Optimal Building." Journal of Architectural Engineering, 7(2), 40-43.

Reifi, M.H.El. and Emmitt, S. (2013). "Perceptions of lean design management." Architectural Engineering and Design Management, 9(3), 195-208.

Smets, M. and Jarzabkowski, P. (2013). "Reconstructing institutional complexity in practice: A relational model of institutional work and complexity." Human Relations, 66(10), 1279-1309.

Stinchcombe, A. L. 1959. "Bureaucratic and craft administration of production: A comparative study." Adm. Sci. Q. 4 (2): 168-187.

Stump, B. and Badurdeen, F. (2012). "Integrating lean and other strategies for mass customization." Journal of Intelligent Manufacturing, 23(1), 109-124.

Ulrich, K.T. and Eppinger, S.D. (2008). Product design and development. McGraw-Hill, NY. U.S.

Vaz, D., Al Bizri, S., and Gray, C. (2008). "The management of the design of modern curtain wall cladding systems." In ARCOM 24th Ann. Conf., 759-768.

Whittington, R. (2006). "Completing the Practice Turn in Strategy Research." Organization Studies, 27(5), 613-634.

Womack, James P. and Jones, Daniel T. (1996). Lean Thinking. Simon \& Schuster, New York, U.S.

World Economic Forum (2016). "Shaping the future of construction: a breakthrough in mindset and technology." World Economic Forum, Switzerland. 